\title{
EMPOWERING NETWORK COLLABORATION TO IMPROVE THE QUALITY OF CARE FOR ISCHEMIC STROKE PATIENTS: RESULTS OF ANGELS EUROPE EXPERIENCE AT SAN CAMILLO FORLANINI HOSPITAL
}

angele

AS12-048

Pozzessere C. ;Corsi F.M.; Pezzella, F.R; Anticoli S.; Scifoni G. ;Bravi, C.; Ferrari, C.; Urso, A.; Guglielmelli, E.; Chierchini, P.; Saggese M.P.; Carfora, M.; lani, C.; Spada P.; Ricciuto G.M.; Mellacina M. ;Nucera P.; Nicolucci, P.; Parrocchia S. ;Casertano L.;

Introduction

In Italy the percentage of thrombolysed patients has raised in the last years, but there are still differences among and within regions. In Lazio Region (5.8 million citizens), Regional Guidance identifies three complexity levels for stroke care, according to the "Hub and Spoke" Model. The Region is divided in 4 catchmen areas (1.8 million citizens per area), each with a II Level Stroke Unit (SU), few I Level SU and several Neurovascular Teams (NVTs). Medical Directors of the Hub Hospitals are responsible for stroke network functioning. The authors' Area has n.1 Hub, n.2 I level SU and 8 NVTs. In 2015 only the Hub Centre was able to administer thrombolysis to eligible patients. In 2016 San Camillo Forlanini Hospital joined the "Angels Europe" initiative.

Method

The authors used "Angels" support to carry out an organizational assessment of the network, to implement self-assessment tools at multiple level and to organise residential training of health care personnel involved in stroke clinical pathway; on site simulations for training purposes were implemented. Organizational support was provided to reengineer stroke care process in spoke and NVTs centres.

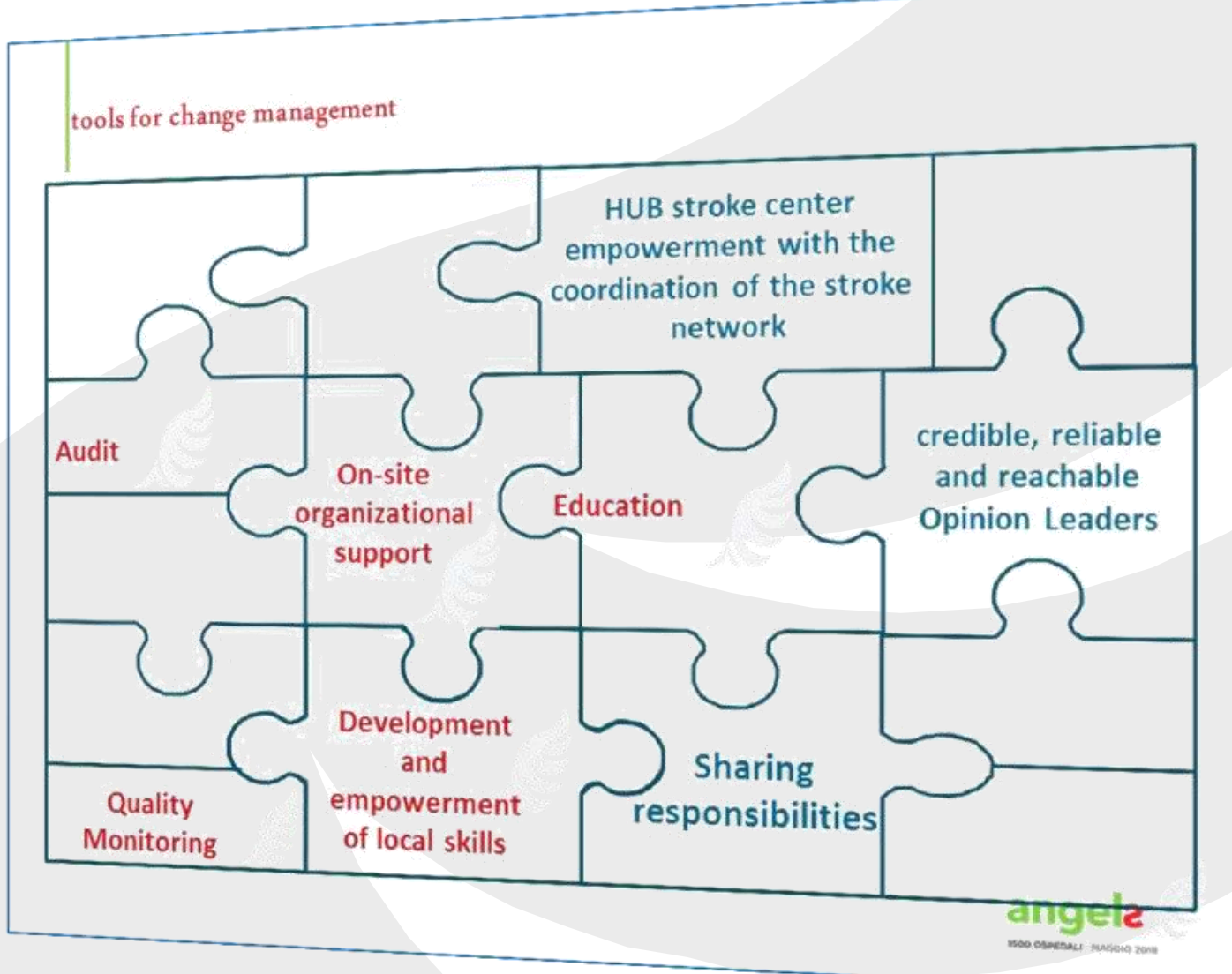

Results

In 2015 thrombolytic procedures were performed only in San Camillo Hub Centre (n.107 treatments). In 2017 the total number of procedures performed in the network was n.191, thus doubling 2015 result; $41.8 \%$ were performed by Hub Centre (n.80) and $58.1 \%$ (n.111) by spokes SU and NVTs.

Discussion and Conclusions

Collaboration with Angels Initiative significantly contributed to improving quality of care and reducing inequalities.

\section{STROKE NETWORK 2015}

Stroke Unit Stroke Unit: Spoke

HUB
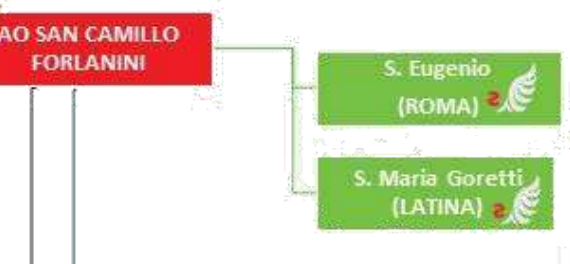

Yellow Stari:Thrombolysis available

White Star: Training forThrombolysis Nostar: Thrombolysis not available
Stroke Ready ER $\quad$ ER

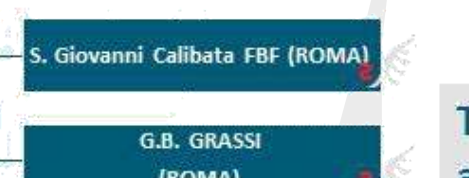

Thrombolysis network area coverage $\approx 10 \%$
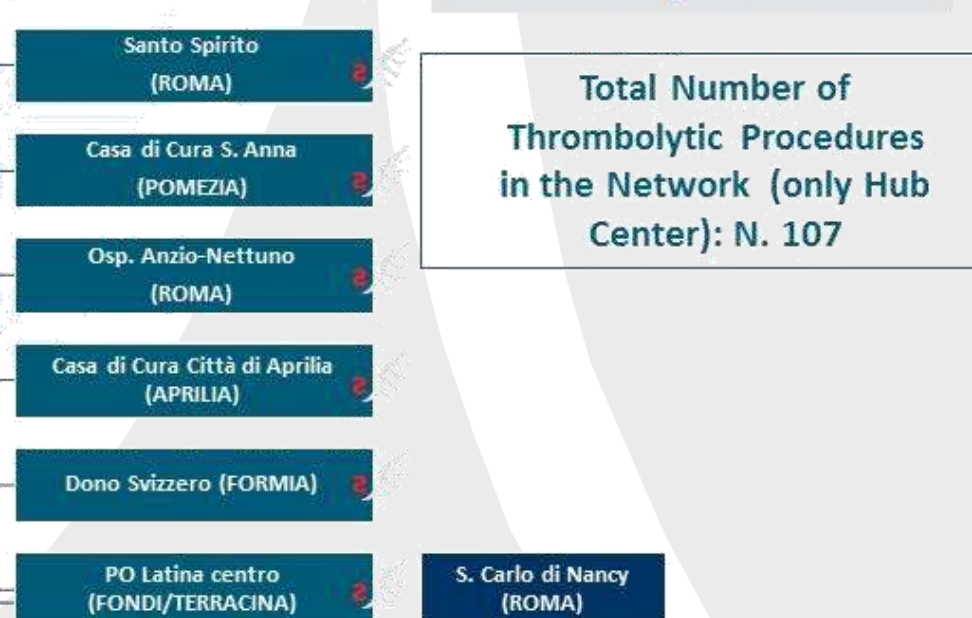

(enter): N. 107

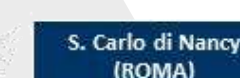

Donabedian A. La qualità dell'assistenza sanitaria: primo volume. Firenze: NIS; 1990. Palmer RH. Measuring clinical performance to provide information for quality improvement. Qual Manag Health Care 1996;4:1-6.

Chassin MR, Galvin RW. The urgent need to improve health care quality. Institute of Medicine National Roundtable on Klazinga N. Re-engineering trust: The adoption and adaption of four models for external quality assurance of health care Shaw C. External quality mechanism for health care: summary of the ExPeRT proj in Heall visita ISO assessment in European Union countries. "International Journal for Quality in Health Care", 2000; 12, 3:169-176. Ferlie E, Gabbay J, Fitzgerald L, et al. Evidence based medicine and organisational change: an overview of some recent qualitative research. In: Ashburner L (ed.) Organisational Behaviours and Organisational Studies in Health Care: reflection o the Future. Basingstoke: Palgrave, 2001, pp.18-42.

Morosini P. Istituto Superiore di Sanità - Indicatori in valutazione e miglioramento della qualità professionale. 2004; iii, $98 \mathrm{p}$ Rapporti ISTISAN 04/29

Currie $G$ and Suhomlinova $O$. The impact of institutional forces upon knowledge sharing in the UK NHS: The triumph of professional power and the inconsistency of policy. Public Admin 2006; 84: 1-30.

PARiHS framework: theoretical and practical challenges. Implement Sci 2008; $3: 1$.

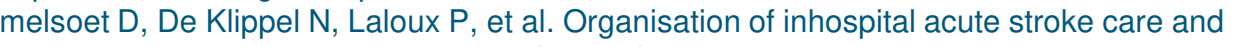
Boaz A, Baeza J, Fraser A, et al. Effective implementation of research into practice: an overview of systematic reviews of the health literature. BMC Research Notes 2011; 4: 212

Bolden R. Distributed leadership in organizations: a review of theory and research. Int J Manage Rev 2011; 13: 251-269. Kazlauskas $\mathrm{H}$, Raškauskienè N, Radžiuvienè R, Janušonis $\mathrm{V}$. Stroke mortality trends in the population of Klaipèda from 199 Guidetti $D$, Spallaziu,

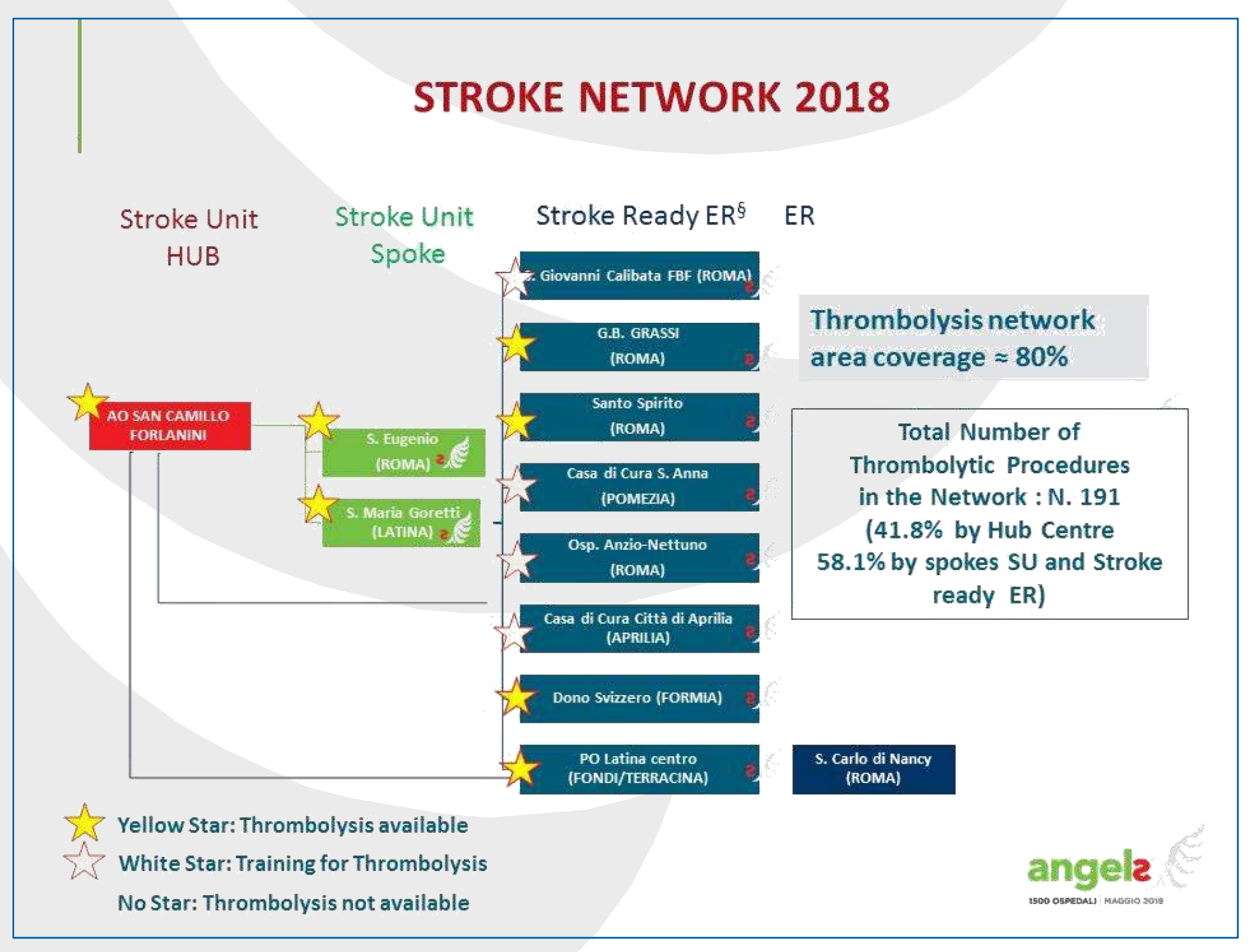

Project Working Group. Updating on Italian stroke units: the "CCM study". Neurol Sci. 2013;34:1087-1092. do 10.1007/s10072-012-1226-3. Gache K, Leleu H, Nitenberg G, Woimant F, Ferrua M, Minvielle E. Main barriers to effective implementation of stroke care pathways in France: a qualitative study. BMC Health Serv Res. 2014;14:95. doi: 10.1186/1472-6963-14-95. Scotish Stroke Care Audit. 2014 National Report. Stroke Services in Scottish Hospitals.

Stroke Association, State of the Nation: Stroke statistics. 2016: London Royal College of Physicians, 2015. SSNAP Annual Report. Care received between April 2015 to March 2016. 2016, Royal College of Physicians: London. L'impatto dell'Ictus in Europa Report King's College London per la Stroke Alliance for Europe (SAFE) 2017

Corrisponding Author: Luca Casertano Icasertano@scamilloforlanini.rm.it - Director Clinica Pathways Area - San Camillo Forlanini Hospital - Circonvallazione Gianicolense 87, 00141 Rome Italy 